\title{
The Impact of Google Apps at Work: Higher Educational Perspective
}

\author{
https://doi.org/10.3991/ijim.v10i4.6181 \\ Mostafa Al-Emran ${ }^{1,2}$, Sohail Iqbal Malik ${ }^{2}$ \\ ${ }^{1}$ Universiti Malaysia Pahang, Pahang, Malaysia \\ ${ }^{2}$ Al Buraimi University College, Al Buraimi, Oman
}

\begin{abstract}
Google Apps brought many opportunities to enhance the work performance in the higher educational settings. This study aims to investigate the impact of Google Apps at work from the perspective of the higher educational institutions. An online questionnaire survey has been prepared and distributed among the academic and administrative staff at Al Buraimi University College, Oman for data collection. The total number of participants was 34. Different statistical analyses were performed on the collected data. Results revealed that the administrative staffs were more positive toward using Google Apps than the academics in performing their work while $58.8 \%$ of the Academics indicated that they are using Google Apps in processing their work. The results of this study indicate that Google Apps are highly perceived by both academic and administrative staffs. This is evidence that these Apps have a significant impact on performing the work in the higher educational settings. Limitations and future work have been addressed.
\end{abstract}

Index Terms-Google Apps, impact, higher education, Oman.

\section{INTRODUCTION}

Google has come up with a Variety of constructive services that help the industry and education to perform their work effectively. A study by [1] stated that Google Apps is considered as one of the web-based services that provide access to various Apps supported by Google at any time and in any place under the coverage of internet connection. Moreover, Google Apps allow a reliable, scalable and highly secure access to the data stored by these Apps. Another study by [2] pointed out that Google Apps facilitated the access to information (whether through webbrowsers or mobile devices) without any supplementary servers or maintenance requirements. One of the major successes of using Google Apps is the usage of mobile devices. Nowadays, mobile devices with the help of smart applications play a vital role in facilitating our work performance.

In the higher educational context, mobile technologies enable all the students, educators and administrative staff to accomplish their tasks in anytime anywhere. A recent study by [3] highlighted in a comprehensive study that 99 $\%$ of the students in both (Oman \& UAE) have mobile devices and $81 \%$ of them were using these devices for their study purpose. The present study is conducted at $\mathrm{Al}$ Buraimi University College (BUC), which is one of the growing Colleges in Oman that is keen to support and implement educational technologies [4] and using Google services for performing their daily work. Due to that reason, this study has focused on this educational institution for examining the impact of using Google Apps at work from the perspective of academic and administrative staffs.

This paper is organized as follows; literature review details the related work in section 2 . Research questions are illustrated in section 3. Section 4 presents the research methodology. The results of this study are depicted in section 5. Conclusion and future work are demonstrated in section 6 .

\section{LITERATURE REVIEW}

A study by [5] introduced Google Apps as collaboration tools among teachers to promote their professional leaning communities. It has been stated that most of the documents are getting stored on Google Apps and are easily accessible by all collaborators.

Another study by [6] introduced Interdisciplinary WebBased Learning Practices into two distinct undergraduate courses (Management of Innovation and Technology and Business Software Applications) by using Google Apps. It has been concluded that Google Apps proved its efficiency to be constructive tools for the students by facilitating their collaboration, communication and sharing while performing their tasks in groups, which in turn supporting their contributions of two separated disciplines.

The authors of [7] stated that "Google Apps have become an inherent part of data processing in universities, ensuring performance and quality management, by facilitating research and cooperation among educational institutions, as well as communication among teaching staff (p. 252)". The authors analyzed the academic environment of the Romanian universities and concluded that there is "an increasing number of higher education providers are migrating to educational platforms built on Google Application support" (p. 252) such as Gmail, calendar, drive, Google plus and sites etc.

Another study by [2] conducted a qualitative study by interviewing eight university professors' about the impact of integrating Google Apps on students' communication and collaboration skills. Results indicated that academics are ready to integrate Google Apps into their strategies, once they will get the sufficient training and professional development. "Professors agreed that collaborative technology was an effective teaching tool and assisted students when working on group and individual projects ( $\mathrm{p}$. 1)".

The authors of [8] conducted a study to determine the usage of Google Apps between IT staff members and their students in a higher Education provider. It has been concluded that the IT staff were using Google apps as a main communication channel among themselves. On the other hand, the usage of the Google Apps among the IT staff 
members and their students is less frequent. Students' lack of trust on the online tools and limited use of electronic information services particularly in first and second years of their study were the underlying reasons contributed to this behavior.

The current available studies are still not sufficient to make judgment on the Google Apps effectiveness and its impact on work. Therefore, this study attempts to investigate further variables for further investigation.

Research Questions

In this study, we are seeking to answer the following questions:

RQ1: How Google Apps are perceived by both academic and administrative staffs?

RQ2: Is there any significant difference among the academic and administrative staffs towards the adoption of Google Apps?

RQ3: Is there any gender differences among the academic and administrative staffs towards the adoption of Google Apps?

RQ4: What is the most affective Google App on academic and administrative staffs in performing their work?

\section{RESEARCH MethodOLOGY}

\section{A. Population and Instrument}

The data was collected via an online questionnaire survey that was distributed among the academic and administrative staff of Al Buraimi University College through their emails. The data was collected between $\left(1^{\text {st }}\right.$ Nov 2015 and $31^{\text {st }}$ April 2016). There are 20 responds from the academic staff while only 14 respond from the administrative staff. The population of the participants is varied between Arabs and non-Arabs, and with different academic degrees (Bachelors, Masters and PhDs). Table 1 represents the participants' demographic data.

\section{B. Survey Structure}

The survey consists of 24 items that are contained within 6 sections. The first section includes personal information about the participants (6 items). The second section consists of items related to Google Apps usage (5 items). The third section includes items related to Gmail usage (4 items). The fourth section entails items regarding Google Calendar usage (3 items). The fifth section contains the items related to Google Drive ( 3 items). The sixth section consists of items related to Google hangouts usage (3 items). A five-point Likert Scale with strongly agree (5), agree (4), neutral (3), disagree (2) and strongly disagree (1) was used to measure all the items within the sections $(3,4,5$ and 6$)$.

\section{Reliability}

Reliability analysis test was computed for all the independent attributes that represent the participants' perceptions towards all the Google Apps via calculating the Cronbach's Alpha according to the conducted studies by [9], [10] and [3]. The calculated Cronbach's Alpha values was (Alpha $=0.905)$ which is greater than 0.7 which in turn indicates that the attributes are highly reliable.

\section{FINDINGS}

RQ1: How Google Apps are perceived by both academic and administrative staffs?
TABLE I.

PARTICIPANTS' DEMOGRAPHIC DATA.

\begin{tabular}{|c|c|c|c|}
\hline Variable & Answers & Frequency & Percentage \% \\
\hline \multirow[t]{2}{*}{ Gender } & Male & 25 & $73.5 \%$ \\
\hline & Female & 9 & $26.5 \%$ \\
\hline \multirow[t]{4}{*}{ Age } & 26 to 35 & 12 & $35.3 \%$ \\
\hline & 36 to 45 & 10 & $29.4 \%$ \\
\hline & 46 to 55 & 9 & $26.5 \%$ \\
\hline & Above 55 & 3 & $8.8 \%$ \\
\hline \multirow[t]{5}{*}{ Qualification } & Secondary School & 1 & $2.9 \%$ \\
\hline & $\begin{array}{l}\text { Diploma/ Advanced } \\
\text { Diploma }\end{array}$ & 1 & $2.9 \%$ \\
\hline & Bachelor & 12 & $35.3 \%$ \\
\hline & Master & 13 & $38.2 \%$ \\
\hline & $\mathrm{PhD}$ & 7 & $20.6 \%$ \\
\hline \multirow[t]{3}{*}{ Experience } & Less than 5 years & 9 & $26.5 \%$ \\
\hline & Between 5 to 10 years & 5 & $14.7 \%$ \\
\hline & More than 10 years & 20 & $58.8 \%$ \\
\hline \multirow[t]{2}{*}{ Staff } & Academic & 20 & $58.8 \%$ \\
\hline & Administrative & 14 & $41.2 \%$ \\
\hline \multirow[t]{2}{*}{ Nationality } & Arab & 25 & $73.5 \%$ \\
\hline & Non-Arab & 9 & $26.5 \%$ \\
\hline
\end{tabular}

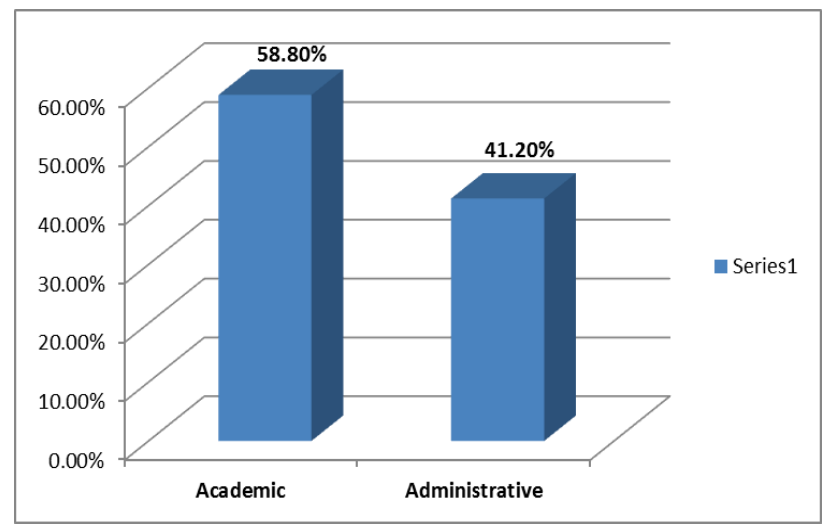

Figure 1. Academic and Administrative usage of Google Apps.

As per (Fig. 1), $58.8 \%$ of the Academic staff shows that they are using Google Apps in processing their work while on the other side, $41.2 \%$ of the administrative staff are doing so. The results are reasonable as most of the academic and administrative staff are using Gmail for communication on daily basis. Moreover, most of the staff are using Google Drive for storing their daily work on the cloud. In addition, some of them are using Google Calendar for preparing events, to-do-tasks and schedule their meetings.

RQ2: Is there any significant difference among the academic and administrative staffs towards the adoption of Google Apps?

According to the studies by [8] and [3], the independent samples $t$-test was computed for examining if there any statistical significant difference among the academic and administrative staff in adopting Google Apps at work. As per (Table 2), results revealed a statistical significant difference among the staff $(p=0.006, p \leq 0.05)$. The administrative staff with the mean score (4.04) are more positive toward using Google Apps than the academics with a mean score (4.00) in performing their work. 
RQ3: Is there any gender differences among the academic and administrative staffs towards the adoption of Google Apps?

According to the studies by [8] and [3], the independent samples $t$-test was computed for investigating whether if there any statistical significant difference among the academic and administrative staff in adopting Google Apps at work in terms of their gender. As per (Table 3), results don't reveal any statistical significant difference among the staff gender ( $p=0.541, p>0.05)$. Findings for this research question indicate that both genders are positive towards using Google Apps at their work with relatively high mean scores.

RQ4: What is the most affective Google App on academic and administrative staffs in performing their work?

Fig. 2 demonstrates the mean score of Google Apps usage at BUC with regard to their academic and administrative staff. Gmail with highest mean score (4.29) represents the most used Google App by both academic and administrative staff. Moreover, Google Drive with the mean score (3.8) represents the second used Google App at work. The results are very reasonable as Gmail is the official communication tool that each faculty member and administrative staff has his/ her own Gmail account and used it through all the communications at work. These results agree with the study by [11] where the author stated that Gmail is the best email service for Google's users. Besides, Google Drive is being used as cloud storage by many faculty and administrative staff instead of using their PCs hard disks due to the ease of access to information.

\section{CONCLUSION}

Recently, Google Apps has a major impact on work performance in general and higher education in specific. This study has been conducted at Al Buraimi University College (BUC) in order to examine the impact of these Apps on work performance with regard to the academic and administrative staffs. An online questionnaire survey has been prepared and distributed to the academic and administrative staffs at BUC through their emails. The total number of participants was $34.73 .5 \%$ of the participants were males and $38.2 \%$ of them were master holders. $58.8 \%$ of them have an experience of more than 10 years. The calculated Cronbach's Alpha values was (Alpha $=0.905)$; this indicates a high reliability. By examining different factors, results indicated that $58.8 \%$ of the Academic staff indicated that they are using Google Apps in processing their work while on the other side, $41.2 \%$ of the administrative staff are doing so. Furthermore, results revealed a statistical significant difference among the staff. The administrative staffs were more positive toward using Google Apps than the academics in performing their work. Moreover, results don't reveal any statistical significant difference among the staff gender while the mean scores for both gender were relatively high; this indicates that both genders are interested in using Google Apps at work. Results demonstrated that Gmail represents the most used Google App by both academic and administrative staff.

The results of this study indicate that Google Apps are highly perceived by both academic and administrative staffs which in turn show that these Apps have a significant impact on performing their daily work. This is evi-
TABLE II.

DIFFERENCES AMONG THE PARTICIPANTS TOWARDS THE ADOPTION OF GOOGLE APPS IN TERMS OF CAREER.

\begin{tabular}{|c|c|c|c|c|c|c|}
\hline Staff & N & Mean & Std. Dev. & t & DF & Sig. \\
\hline Academic & 20 & 4.0000 & 0.43259 & \multirow{2}{*}{-0.161} & 32 & \multirow{2}{*}{$\mathbf{0 . 0 0 6}$} \\
\cline { 1 - 5 } Administrative & 14 & 4.0476 & 1.22549 & & & \\
\hline
\end{tabular}

TABLE III.

DIFFERENCES AMONG THE PARTICIPANTS TOWARDS THE ADOPTION OF GOOGLE APPS IN TERMS OF GENDER.

\begin{tabular}{|c|c|c|c|c|c|c|}
\hline Gender & N & Mean & Std. Dev. & t & DF & Sig. \\
\hline Male & 25 & 3.9867 & 0.91530 & -0.378 & 32 & $\mathbf{0 . 5 4 1}$ \\
Female & 9 & 4.1111 & 0.60093 & & & \\
\hline
\end{tabular}

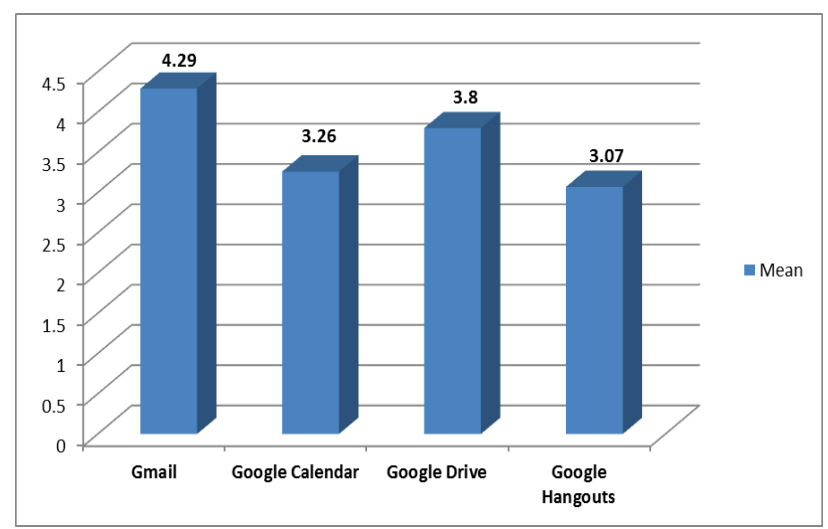

Figure 2. Academic and Administrative usage of Google Apps.

dence that Google Apps are facilitating the higher educational environments in performing their work. As a limitation, the total number of participants is very low in order to gain a comprehensive insight about these Apps. Future work will focus on exploring the impact of these Apps from the perspective of students as it will add more value to the current research.

\section{REFERENCES}

[1] Sviridova, T., Sviridova, L., \& Tymoshenko, B. (2011). Google Apps as solution of communication issues in educational process. In Perspective Technologies and Methods in MEMS Design.

[2] Cahill, J. L. (2014). University Professors' Perceptions About the Impact of Integrating Google Applications on Students' Communication and Collaboration Skills. Journal of Research Initiatives, $1(2), 7$.

[3] Al-Emran, M., Elsherif, H. M., \& Shaalan, K. (2016). Investigating attitudes towards the use of mobile learning in higher education. Computers in Human Behavior, 56, 93-102. http://dx.doi.org/10.1016/j.chb.2015.11.033

[4] Al Emran, M., \& Shaalan, K. (2014). E-podium Technology: A medium of managing Knowledge at Al Buraimi University College via M-learning. In BCS international IT conference.

[5] Kaimuloa Bates, B. (2011). Using Google Apps in Professional Learning Communities. Proceedings of the $16^{\text {th }}$ Annual TCC Worldwide online conference, Hawai, USA.

[6] Ktoridou, D., \& Eteokleous, N. (2013, March). Interdisciplinary Web-based learning practices in higher education. In Global Engineering Education Conference (EDUCON), 2013 IEEE (pp. 536539). IEEE. http://dx.doi.org/10.1109/educon.2013.6530157

[7] Ionita M, Pastae V, \& Stoica A. (2014). Benefits of Setting up Academic Portals on Google Apps. Proceedings of the $10^{\text {th }}$ International Scientific Conference eLearning and software for Education, Romania, pp. 252-255.

[8] Owayid, A. M., \& Uden, L. (2014). The Usage of Google Apps Services in Higher Education. In Learning Technology for Education in Cloud. MOOC and Big Data (pp. 95-104). Springer Inter- 
national Publishing. http://dx.doi.org/10.1007/978-3-319-106717 ? 9

[9] Zhang, X., De Pablos, P. O., \& Xu, Q. (2014). Culture effects on the knowledge sharing in multi-national virtual classes: A mixed method. Computers in Human Behavior, 31, 491-498. http://dx.doi.org/10.1016/j.chb.2013.04.021

[10] Al-Emran, M., \& Shaalan, K. (2015). Attitudes towards the use of mobile learning: a case study from the gulf region. International Journal of Interactive Mobile Technologies (iJIM), 9(3), 75-78. http://dx.doi.org/10.3991/ijim.v9i3.4596

[11] Ferreira, J. M. M. (2014, February). Flipped classrooms: From concept to reality using Google Apps. In Remote Engineering and Virtual Instrumentation (REV), 2014 11th International Conference on (pp. 204-208). IEEE.

\section{AUTHORS}

Mostafa Al-Emran is a PhD student in Computer Science at Universiti Malaysia Pahang. He got his MSc in Informatics from The British University in Dubai with a distinction level along with the top Academic Excellence Award. Al-Emran got his Bachelor degree from Al Buraimi University College with the first honor degree in Computer Science. He is currently the Head of Technical Support \& Electronic Services Sections at Al Buraimi University College. He is working on different research areas in Computer Science such as: Mobile Learning, Knowledge Management, Educational Technology, Data Mining and Data Analysis. (malemran@buc.edu.om).

Sohail Iqbal Malik got his $\mathrm{PhD}$ in Computer Science from Deakin University, Australia in 2016. He is currently the head of IT department at Al Buraimi University College, Oman. His research interest includes: Computer Education, Technology in Education, Knowledge Management and Web Learning. (sohail@buc.edu.om).

Submitted, 28 August 2016. Published as resubmitted by the authors on 01 October 2016. 